\title{
La representación de la pobreza en la prensa (Estudio de caso en la prensa tapatía)
}

\author{
The representation of poverty in the press \\ (Case study in Guadalajara Press)
}

\author{
Dra. María Auxiliadora Gabino Campos \\ Universidad Autónoma de San Luis Potosí \\ maria.gabino@uaslp.mx \\ Lic. Roberto Carlos Contreras Román \\ Universidad del Valle de Atemajac \\ alcohot@hotmail.com
}

Recibido: 20 de noviembre de 2011

Aceptado: 15 de diciembre de 2011

\section{Resumen}

El objetivo primario de la prensa, desde su nacimiento, fue difundir mensajes. A medida que se modernizó y surgieron los diarios impresos, el contenido de los mensajes se diversificó con un criterio que antepone invariablemente una temática sobre otra.

La prensa de nuestros tiempos se caracteriza porque en sus páginas aminora la representación de ciertos sectores de la sociedad, como es el caso de los que viven en condiciones de pobreza; donde se vislumbra como se acalla la voz de los sectores desprotegidos y se les priva de influir en la conciencia pública.

Ante esta situación se plantea una investigación con alcance descriptivo desde el enfoque cualitativo donde se pretende evidenciar, a través del análisis de contenido, cómo se refleja la pobreza en la prensa y para ello, se eligieron los tres diarios de mayor tiraje de la Zona Metropolitana de Guadalajara, Jalisco, México (El Informador, Público y Mural) durante el mes de octubre del 2010.

Los resultados obtenidos muestran como la pobreza es representada en la prensa analizada. Se da respuesta a qué tan rentable resulta este sector para los intereses del medio, y a la forma de hacer periodismo de cada uno, lo que se proyecta de la masa; lo cual denota como la prensa no contesta a este sector socio-económico, y como el periodismo se aleja de su papel social. 


\section{Abstract}

Eversince its creation, the main purpose of Press was to spread messages. As it evolved, newspapers were created and the content of messages became more diverse and greater, although always marked by criteria that put certain themes before others.

Today's press is characterized for diminishing the representation of certain social strata. Namely the ones that live in poverty which voice is silenced and therefore can't influence public conscience.

Because of this situation it is necessary to conduct a descriptive investigation with quality approach to evidence how poverty is reflected in press. For this reason the 3 most widespread newspapers in the Metropolitan zone of Guadalajara (Jalisco, México) were selected: El informador, Público and Mural.

The results show how poverty is represented in the media, how profitable this sector for the interests of the media and the type of journalism conducted by each newspaper. It is evident that the media do not satisfy the socio-economical strata as it ignores its social role.

Palabras claves: Periodismo, pobreza, análisis de contenido, conciencia pública.

Keywords: Journalism, poverty, content analysis, public awareness.

\section{Introducción}

La pobreza para la ONU es "la condición caracterizada por una privación severa de necesidades humanas básicas, incluyendo alimentos, agua potable, instalaciones sanitarias, salud, vivienda, educación e información. La pobreza depende no sólo de ingresos monetarios sino también del acceso a servicios."(ONU, 1995: 57)

Mientras para el Banco Mundial, los pobres son la población que vive "con menos de US\$1.08 diario, precios internacionales del 1993 (equivalente a US\$1 en precios de 1985, ajustado por la paridad de poder de compra). Las tasas de pobreza son comparables entre países, pero como resultado de una revisión de los tipos de cambio". (Banco Mundial, s.f.)

Existen multiples definiciones de pobreza y diferentes formas de medirla. Las carencias a través de los ingresos y el consumo han sido la forma tradicional de medir la pobreza como hemos leído en las definiciones anteriores, pero hay otros estudios que han abordado la pobreza desde perspectivas diferentes como las que siguen.

Segùn Paul Spicker (2009), las ciencias sociales entienden la pobreza con al menos doce sentidos específicos, los cuales se sobreponen. La pobreza se categoriza, en tres marcos 
conceptuales fundamentales dependiendo de los condicionantes: pobreza material, pobreza económicos o pobreza sociales. Cada una de éstas a su vez se subdividen

Desde una perspectiva multidimensional, el Banco Mundial planteó en su estudio Voces de los pobres, la pobreza desde los pobres y para ello, participaron más de 20 mil pobres de 23 países. Sus respuestas se agruparon "en diez dimensiones interrelacionadas de la pobreza: estilos de vida precarios, áreas excluidas, problemas físicos, relaciones de género, problemas en las relaciones sociales, falta de seguridad, abuso por parte de aquellos en el poder, instituciones des-empoderadoras, organizaciones comunitarias débiles y limitaciones en las capacidades de los pobres." (Spicker, 2009, p. 303)

Los resultados de dicha investigación muestran que "los problemas identificados por la población pobre no son los mismos que otras personas identifican como "pobreza", pero de todas maneras estos problemas son importantes para las personas afectadas. Entonces, este enfoque para entender la pobreza tiene un fuerte compromiso: trabajar desde la perspectiva de los pobres." (Spicker,2009, p. 303)

Históricamente, las representaciones de la pobreza en la prensa han variado significativamente de acuerdo con los grupos que poseen poder simbólico (Echeverría: 2007, p. 272), entendido éste como "la capacidad de intervenir en el transcurso de los acontecimientos, para influir en las acciones de los otros y crear acontecimientos reales, a través de los medios de producción y transmisión de formas simbólicas" (Thompson, 1998, p. 34).

Rossini (2002) encontró que "las mutaciones de las actitudes y sentimientos han transformado imperceptiblemente las representaciones de pobreza de un estatuto santificante en la época medieval a la condenación y connotación negativa actual" (p. 243) Esa representación, agrega el investigador, "ha pasado por la aceptación pasiva de las condiciones sociales precarias, asociándolo con la virtud, hasta la identificación con la condición obrera en la Revolución Industrial, que resulta no solamente percibida como negativa, sino peligrosa para el mantenimiento del orden social." (p. 243)

En nuestros tiempos, los medios reafirman el estado de las cosas de forma desigual que han construido, como lo han hecho otras instituciones sociales a lo largo de la historia, esta vez mediante la valoración de la posesión material y la precariedad como defecto individual (Echeverría, 2007), y por lo cual se gana determinado espacio en tal o cual medio.

En 2007, la Escuela de Comunicaciones de la Universidad de Viña del Mar presentó El desafío de (re)construir la noticia, un diagnóstico acerca de la forma en que la prensa de la 
región mira, aborda e informa los hechos vinculados con la pobreza, la exclusión y la desigualdad.

Este estudio muestra que la tendencia de la prensa de Valparaíso es afrontar los temas de pobreza no de manera directa, sino asociada. En el análisis se muestra que $59 \%$ de las publicaciones fueron asociadas, es decir, abordaron otros temas relacionados; el $29 \%$ se centró en la pobreza, y $12 \%$ fue temático, esto es, se encontró en ellas un concepto de pobreza. Los temas que más abundaron fueron educación, seguidos por economía y desarrollo.

También, se detecta que los pobres aparecen en los periódicos estudiados en su mayoría como sujetos receptores. A través de los discursos, pareciera que se les ha imposibilitado para dar; que sólo son capaces de recibir. También sustenta la teoría de que las personas en situación de pobreza, al ser representadas en calidad de receptoras de la asistencia de otros, pueden ver aún más difícil su situación, y por consiguiente, el salir de dicha situación de pobreza se dificulta.

El diagnóstico de Viña del Mar (2007), con respecto a la actitud de las personas en situación de pobreza, muestra que la tendencia predominante en las noticias es mostrarlas en calidad de receptoras $(50 \%)$ de la ayuda o asistencia de otros en la solución de sus problemas, es decir, en una situación pasiva frente a su situación. Además, añade que es significativa la cantidad de noticias "sin vocería", esto es, noticias carentes de la voz de los pobres.

En cuanto al tipo de noticias que abordan el tema de la pobreza, el estudio refiere que la mayoría de las noticias vinculadas con dicho tema corresponden a crónicas informativas o a breves, en tanto que una minoría corresponde a géneros con más desarrollo y profundidad, como reportajes o entrevistas. Esta situación está dada también por la escasez general de artículos noticiosos de más largo aliento en los diarios analizados, en beneficio de formatos más cortos que permitan mayor cantidad de noticias por edición. Las crónicas y los breves, sin embargo, no permiten investigar ni desarrollar los temas sobre la pobreza en forma más integral.

La lucha por el poder y la clase social también contribuyen a que los pobres no tengan lugar en los periódicos. En una sociedad en la que existen desigualdades sociales, y en una sociedad de clases existe una que detenta la riqueza y el poder que defiende esta riqueza. Esta clase está interesada en que no se noten las desigualdades sociales, y si se advierten, que se piense que son cosas naturales producidas por Dios y no por los hombres.

La Dra. Hernández (2002), en su trabajo denominado "La nota roja, espacio de los nadies", apunta que las clases bajas son excluidas y marginadas por medio de la nota roja de los 
periódicos, a diferencia de las elites, que ocupan las primeras planas, o las secciones de sociales.

Los pobres son representados por los no pobres. Las características que se le atribuyen a las clases más bajas las determinan los actores sociales más poderosos (a quienes pertenecen las instituciones mediadoras), y son ellos quienes 'pueden en mayor o menor medida determinar quién puede decir (o escribir) qué, a quién, acerca de quién, de qué manera y en cuáles circunstancias'. (Hernández, 2002, p.2)

Hernández señala que al igual que las grandes ciudades son en el mundo contemporáneo, espacios de representación de las grandes contradicciones sociales, los medios juegan un papel idéntico al configurar el espacio público, la zona de las definiciones y el único en que se cristalizan las representaciones sociales, se convierten en lugares exclusivos. Advierte que "no es que en ellos las imágenes non gratas no aparezcan, sino que éstas son confinadas a la periferia: su vocación es dar coherencia a un sistema en el cual las élites son las que ocupan los sitios centrales. (Hernández, 2002, p.2)

Parte de esto es debido a la ausencia de un fundamento ético del quehacer periodístico. Por ello, son los grupos sociales y económicos más vulnerables los que aparecen en este tipo de noticias.

De este trabajo también vale destacar que en los periódicos "la tragedia de los sectores más pobres es vista con curiosidad y morbo, pero no se intenta comprenderla. Por tal motivo es importante evidenciar, cuantificar y cualificar esta problemática que en la vida cotidiana se ve como algo 'natural' y es posible debido a que existe poco espacio de impunidad, un Estado de derecho fragmentado." (Hernández, 2002, p.3)

Los pobres son con frecuencia representados creando una imagen y un vínculo con la delincuencia, las adicciones y la violencia, así como la idea de que entre dicho sector impera la ignorancia, lo que deriva en un clima de desigualdad y por consiguiente, impone mayores dificultades de superación.

Los diarios son empresas, y como tales representan intereses; no obstante, su tarea es emitir mensajes y su negocio es la comunicación. Dicho de otro modo: el negocio de los mensajes. Por ello, cuando se utiliza un modelo desigual -en el campo social- para la construcción de las noticias, se puede hablar de un problema en la comunicación. Además los poderes no quedan exentos de esta dependencia de la opinión publica: "Los organismos públicos no son entes aislados de esta realidad, por lo que no pueden vivir ajenos a la visibilidad y justificación social de la necesidad de su existencia." (Alcoceba, 2010) 
Para aclarar un poco más este problema, hay que tener en cuenta que los intereses que imperan en cada empresa mediática -en este caso la prensa- se ven reflejados en el espacio que designan en sus páginas para los diversos temas noticiosos.

En la jerarquía que prevalece en las páginas de un diario, resalta que los sectores desprotegidos de la sociedad son relegados también en cuestión de espacios, lo que da lugar, primeramente, a una significativa desigualdad en cuanto a noticias publicadas por temáticas, siendo el tema de la pobreza uno de los más escondidos.

De la representación mediática, surgen estereotipos y prejuicios con las personas que viven en condiciones de pobreza, y que aparecen en la nota roja como ladrones, personas violentas, poco inteligentes e incultas, se crea una imagen -por lo general negativa- que les dificulta aún más el salir de la situación en la que se encuentran.

Hasta 2010, 46.2\% de la población mexicana era pobre multidimensional, es decir, había 52 millones de personas que tenían carencia en al menos uno de los siguientes rubros: educación, salud, seguridad social, calidad de la vivienda, servicios básicos en la vivienda y alimentación (carencias sociales) y un ingreso inferior a la Línea de Bienestar Económico (LBE). El 10.4\% de la población (11.7 millones) vivía en pobreza extrema. (CONEVAL, 2010)

En Jalisco (México), donde se localiza la Zona Metropolitana de Guadalajara, el 34.3\% de la población vivía en condiciones de pobreza multidimensional, con un promedio de 2 carencias sociales. El $54.8 \%$ de la población jalisciense señalaba carencia por acceso a la seguridad social; $35.2 \%$, por acceso a los servicios de salud; $20.2 \%$ rezago educativo; $22.1 \%$, escasez por acceso suficiente a la alimentación; $6.7 \%$ insuficiencia por calidad y espacios de la vivienda, y $9.5 \%$, carencia por servicios básicos en la vivienda. (CONEVAL, 2010)

Cuando casi la mitad de la población en México vive en condiciones de pobreza, bien vale preguntarse por qué los pobres no son noticia, si lo que se hace en los diarios es "periodismo de elite" y si realmente se cumple con el servicio a la sociedad y de informar a las masas.

El humanismo ha quedado relegado en nuestra sociedad. Guadalajara (Jalisco) no es la excepción, donde a los pobres se les voltea la cara ya sea en persona o en espacios concretos como son en los medios de comunicación. Pareciera paradójico que aunque casi la mitad de la población en México vive en condiciones de pobreza, de acuerdo con cifras del Coneval, los medios de comunicación reflejan otra realidad.

Ante la situación expuesta se plantea la siguiente pregunta de investigación: ¿Cuál es la presencia de la pobreza en la prensa tapatía?; y como objetivo, determinar la imagen de los pobres en la prensa de la Zona Metropolitana de Guadalajara (Jalisco, México). 
Este trabajo se sustenta teóricamente a través de la teoría del establecimiento de la agenda mediática y la espiral del silencio, aunque se tuvo que hacer una incidencia en la opinión pública, y ahondar en la explicación de este fenómeno.

... el público tiende a incluir o excluir de sus propios conocimientos lo que los medios de comunicación incluyen o excluyen de sus propios contenidos. El público asigna a ellos una importancia igual y es consecuente con el énfasis atribuido por los medios a esos acontecimientos, problemas o personajes. La explicación es que la comprensión de la gente sobre gran parte de la realidad social se determina por la acción cotidiana de los medios de comunicación. (Meyer, 2009)

Por consiguiente, por medio de la exposición masiva de temas, los medios de comunicación organizan la agenda mediática de las personas, en la que el tema de la pobreza puede adquirir menor importancia que otros, lo que se refleja en la cognición de las personas y en su realidad circundante, de la misma forma en que aparece publicado por importancia en las páginas de un diario.

Importante aspecto juegan los argumentos de las personas que viven en situación de pobreza en los documentos periodísticos, puesto que cuando existe la tendencia a no dar voz a este sector de la sociedad, sus intereses no se ven reflejados en la prensa, lo que de acuerdo con la teoría de la espiral del silencio puede interpretarse como conformidad y se presta para que el argumento predominante por repetición sea aceptado como correcto, demostrando una espiral del silencio en contra de este sector de la sociedad en un determinado tema.

\section{Aproximación al marco metodológico y alcance}

"El análisis de contenido es un método que permite investigar con detalle y profundidad cualquier material de la comunicación humana" (Frutos Esteban, 2008) y èste es el elegido para abordar la forma en que tres diarios de la Zona Metropolitana de Guadalajara (México) representan la pobreza.

Para realizar esta investigación, se utilizará como muestreo material de los tres diarios que tienen mayor representatividad en la Zona Metropolitana de Guadalajara (Público, El Informador y Mural), durante el mes de agosto de 2010. Estos medios fueron elegidos por ser los más representativos de la Zona Metropolitana de Guadalajara y del Estado de Jalisco. Difieren en su línea editorial así como en los segmentos de mercado a los que van dirigidos, lo que incide en sus publicaciones y en el modo en que representan la realidad. 
La mayoría de los estudios que se han realizado en cuanto a la pobreza y la prensa, tienen que ver con los estereotipos que se generan en cuanto a su representación, y en menor medida en cuanto a qué tipo de espacios ocupan en la prensa, y cuánta área se reserva para estos sectores que no representan grandes ventas para la empresa noticiosa.

Realza la importancia para la realización de este estudio, conocer las perspectivas predominantes que determinan la agenda mediática de cada medio, y si los argumentos que estas personas tienen en la prensa son suficientes para influir en la conciencia pública o si, por el contrario, se genera una espiral del silencio debido a la falta de argumentos, que puede interpretarse como conformidad.

La investigación beneficia a la sociedad puesto que permite conocer cómo la prensa de la Zona Metropolitana de Guadalajara representa al sector que vive en condiciones de pobreza e incentivar hacia un periodismo más equitativo entre las clases sociales, para que estas personas tengan mayor voz y representatividad, así como la oportunidad de influir en la conciencia pública.

\subsection{Diseño de la Investigación}

Para realizar el análisis de contenido, se seleccionó como muestra aleatoria los documentos publicados en un lapso de 31 días, correspondiente al mes de agosto de 2010, en los diarios El Informador, Público y Mural, que circulan en el Estado de Jalisco. Estos diarios constituyen las unidades de muestreo y fueron seleccionados por ser los de mayor penetración en el Estado. El criterio básico a partir del cual se definió el periodo de análisis tiene que ver con los objetivos de la investigación.

Para fijar límites a la información contextual que puede incorporarse a la descripción de una unidad de registro, se tomó como unidades de contexto la sección que agrupa la información local en los tres diarios a analizar, esto es, la sección "Local", en El Informador; "Ciudad y Región" en Público, y "Comunidad" en Mural, así como las portadas principales de los diarios referidos. Las unidades de registro a analizar son los documentos que constituyen las secciones de los diarios referidos.

Dado que el objeto de estudio lo constituyen notas periodísticas, se contemplan los siguientes criterios de inclusión.

- Que los textos se hayan publicado en el mes de agosto de 2010.

- Que los textos aborden el tema de la pobreza o que los personajes implicados se encuentren en situación de pobreza. 
- Que las notas periodísticas hayan sido publicadas en los diarios Público, Mural y El Informador.

- Que las notas hayan sido publicadas en la sección correspondiente a los temas locales, esto es, en el caso de Público, la sección "Ciudad y región"; en Mural, "Comunidad", y en El Informador, "Local".

- Se admitirán todos los géneros periodísticos.

Se tomaron como criterios de no inclusión

- Todos aquellos textos que no correspondan a géneros periodísticos.

- Todos aquellos textos que no correspondan a las secciones correspondientes a la información local de los diarios mencionados para la investigación.

- Todas aquellas notas que no toquen el tema de la pobreza, directa o indirectamente.

- Todas aquellas notas que no se hayan publicado en el mes de agosto de 2010.

- Publirreportajes.

Debido a que el análisis se centra en un cúmulo de notas periodísticas, cuya naturaleza se considera invariable en curso del estudio, se puede determinar que no hubo exclusiones.

Las categorías de análisis fijadas son: los datos de identificación, estructura formal y aspectos del contenido, de donde destacan las variables:

- Género periodístico

- Perspectiva de la temática general del contenido

- Adjetivos calificativos referidos a los personajes en condiciones de pobreza

- Origen de los personajes en condiciones de pobreza

- Género de los personajes en condiciones de pobreza

- Carencias sociales identificadas

- Papel de los personajes en condiciones de pobreza

- Existencia/ausencia de argumentos de los personajes en condiciones de pobreza

- Papel de los personajes en condiciones de pobreza en las imágenes

- Solución a la problemática expuesta 


\section{Resultados y discusión}

A partir del análisis en las unidades de contexto, se obtiene como unidades de registro un total de 57 documentos, de los cuales 14 (24.56\%) corresponden a El Informador; 25 (43.85\%) a Mural, y $18(31.57 \%)$ a Público.

Durante agosto de 2010, Mural publicó el mayor porcentaje de documentos en los que se identifica pobreza (43.85\%), seguido por Público (31.57\%). El Informador tiene el menor porcentaje $(24.56 \%)$ de estos documentos publicados durante el mes en cuestión.

\subsection{Perspectiva de la temática general del contenido}

En El Informador, los documentos en los que se identifica pobreza son abordados en mayor medida con una perspectiva Política o Médico-sanitaria en igual porcentaje. Le sigue la Social (14.28\%) en igual porcentaje que la Jurídica, y la Laboral-sindical, con el mismo porcentaje que la Administrativa. En Mural predomina la perspectiva Social en $58 \%$ de estos documentos. Le sigue la Jurídica (12\%) y las perspectivas Política y Médico-sanitaria en igual porcentaje. En menor medida se registran las perspectivas Seguridad-policial (4\%), y Laboral-sindical, en tanto que en Público, en $33.31 \%$ de los documentos analizados se registra la perspectiva Social. Le sigue la Jurídica (30.54\%), y Seguridad-policial (16.66\%). En este medio se identificó un documento abordado desde la perspectiva Ecológica (2.77\%).

\subsection{Adjetivos calificativos referidos a los personajes en condiciones de pobreza}

En esta variable no se identificó ningún adjetivo al referirse a las notas analizadas a los personajes en condición de pobreza, lo que permite valorar que los diarios en estudio tienen una redacción al respecto objetiva, ya que no dan valoraciones a través de los adjetivos.

\subsection{Origen de los personajes en condiciones de pobreza}

En los tres diarios predominan los personajes originarios de la Zona Metropolitana de Guadalajara. Mural tiene el mayor porcentaje (42\%) de los que registran personajes originarios de la Zona Metropolitana de Guadalajara, y también de los que registran personajes que tienen su origen en la Periferia (36\%). Es el único de los tres medios analizados que registra personajes de origen extranjero, pero ninguno de origen Indígena.

Público tiene porcentajes iguales de documentos en los que se registran personajes originarios de la Zona Metropolitana de Guadalajara (33.33\%), y de la Periferia. También tiene el mayor porcentaje de documentos en con personajes de origen Indígena, seguido por El Informador. 


\subsection{Género de los personajes en condiciones de pobreza}

En El Informador y en Mural predominan los personajes del género masculino. En El Informador, los personajes del género masculino alcanzan el mayor porcentaje en los documentos en los que se registra pobreza, y en contraste, los personajes del género femenino alcanzan un menor porcentaje de presencia en estos documentos.

En Público, los personajes del género femenino tienen mayor presencia en los documentos en los que se registra pobreza; los del género masculino registran el menor porcentaje de presencia comparado con Muraly El Informador.

\section{a. Carencias sociales identificadas}

En los documentos analizados en El Informador, Mural y en Público es predominante la carencia por Acceso a la seguridad social, seguida por carencia por Calidad y espacios de la vivienda, y carencia por Acceso a los servicios básicos en la vivienda. En menor medida se identifica carencia por Acceso a la alimentación, y por Acceso a los servicios de salud.

En los documentos de Mural destaca el rezago educativo, aunque en menor medida que las carencias por acceso a la seguridad social, y por calidad y espacios de la vivienda.

\subsection{Papel de los personajes en condiciones de pobreza}

En El Informador es predominante, casi total, que los personajes en situación de pobreza tienen un papel secundario. Mural y Público registran más equidad, siendo éste último el que muestra mayor equilibrio de porcentajes en esta variable.

\subsection{Existencia/ausencia de argumentos de los personajes en condiciones de pobreza}

Tanto en El Informador como en Mural y en Público predomina la ausencia de argumentos de los personajes en condiciones de pobreza. No obstante, en El Informador se registra Ausencia de argumentos en el $100 \%$ de los documentos analizados. Público registra mayor porcentaje de Existencia de argumentos, ligeramente por encima de Mural.

\subsection{Papel de los personajes en condiciones de pobreza en las imágenes}

Tanto en El Informador, como en Mural y en Público es predominante que los personajes jueguen un papel principal en las imágenes. Público registra el mayor porcentaje con este indicador, en contraste con El Informador.

Mural registra el mayor porcentaje de imágenes en las que los personajes en condiciones de pobreza tienen un papel secundario, seguido por El Informador, aunque éste último tiene un mayor porcentaje de notas sin apoyo gráfico. 


\subsection{Solución a la problemática expuesta}

Los textos analizados en El Informador, Mural y Público son predominantemente explicativos, es decir, no ofrecen una solución a la problemática expuesta. Mural registra el mayor porcentaje de documentos que ofrecen una solución a la problemática expuesta.

\section{Conclusiones}

La forma en que la pobreza es representada en la prensa de la Zona Metropolitana de Guadalajara responde a qué tan rentable resulta este sector para los intereses del medio, y a la forma de hacer periodismo de cada uno, lo que se proyecta hacia las masas en las publicaciones.

El silencio de los pobres es dominante en la mayoría de los textos. En el caso de El Informador, el $100 \%$ de los textos analizados registra ausencia de argumentos por parte de los personajes en condiciones de pobreza, lo que deja ver una espiral del silencio en su contra en todas las temáticas registradas: política, económica, social, laboral-sindical, jurídica, administrativa y médico-sanitaria. En el caso de Mural, 68\%, y en Público, $66 \%$ de los documentos analizados reflejan esta tendencia. Dado que el silencio también puede interpretarse como conformidad, al mantenerse el proceso en espiral y dominar un punto de vista en los documentos, el otro está condenado a desaparecer de la conciencia pública.

Es preciso replantear los modelos de comunicación con los que se representa al sector de la sociedad que vive en condiciones de pobreza, a fin de que la realidad que reflejan los medios coincida con la que viven estas personas, se cumpla el derecho de igualdad entre clases sociales y equidad de género, en razón de otorgarles mayores oportunidades para expresar sus opiniones y propuestas, a fin de incidir en la opinión pública.

\section{Referencia bibliográfica}

Alcoceba Henando, J.A. (2010): "Análisis de las notas de prensa institucionales y su visibilidad en la prensa, en Revista Latina de Comunicación Social, 65. La Laguna (Tenerife): Universidad de La Laguna, páginas 354 a 367, recuperado el 12 de octubre de 2011, de http://www.revistalatinacs.org/10/art2/905 Complutense/27 Alcoceba.html DOI: 10.4185/RLCS-65-2010-905-354-367

Banco Mundial (s.f.): "Definiciones de los objetivos de desarrollo del milenio", recuperado el 12 de noviembre de 2011, disponible en http://www.bancomundial.org/temas/omd/definiciones.htm 
Consejo Nacional de Evaluación de la Política de Desarrollo Social, CONEVAL. (2010): Pobreza 2010. México: CONEVAL. Recuperado 5 marzo de 2011 de http://www.coneval.gob.mx/cmsconeval/rw/pages/medicion/pobreza 2010.es.do

Echeverría Victoria, M. (2007): "Representaciones periodísticas de la Pobreza: perspectivas teóricas para una agenda de investigación", en XIV Anuario de Investigación en Comunicación. México: CONEICC.

Frutos Esteban, F. J. (2008): "El análisis de contenido y la organización de repertorios culturales: El caso de las placas de linterna mágica", Revista Latina de Comunicación Social (63), 265-276. España: Universidad de La Laguna (Tenerife), recuperado 24 de octubre de 2011, de http://www.revistalatinacs.org/ 2008/21 30 Salamanca/Francisco Javier Frutos.html

Hernández García, S. (2002): Nota Roja, el espacio de los nadies, análisis de los procesos de inclusión-exclusión en la sección policíaca de tres periódicos oaxaqueños. México: Instituto de Estudios Superiores de Oaxaca, Oaxaca de Juárez.

Universidad Central de Venezuela (1967): El Imperio de la noticia, algunos problemas de la información en el mundo contemporáneo. Venezuela: Universidad Central de Venezuela.

Meyer, J. A. (2009): "Establecimiento de agendas en medios de comunicación: Repercusiones del escándalo mediático Marín-Nacif-Cacho." Revista Latina de Comunicación Social, 64, 15- 28. España: Universidad de La Laguna (Tenerife), recuperado el 17 de octubre de 2010, de http://www.revistalatinacs.org/09/art/02 80005 Puebla/Jose Antonio Meyer Rodriguez.ht $\underline{\mathrm{ml}}$

ONU (1995): The Copenhagen Declaration and Programme of Action, en Pobreza Un glosario internacional. (Ed. Spicker, Alvarez y Gordon) Buenos Aires: CLACSO, agosto de 2009 (Edición español), recuperado el 13 de octubre de 2011 de http://bibliotecavirtual.clacso.org.ar/ar/libros/clacso/crop/glosario/

Rossini, S. (2002): Les pauvretés chachées en Suisse. Analyse qualitative de processus de précarisation et perspectives d'action sociale, en Echeverría Victoria, M. (2007): "Representaciones periodísticas de la Pobreza: perspectivas teóricas para una agenda de investigación", en XIV Anuario de Investigación en Comunicación. México: CONEICC.

Spicker, P. (2009): "Definiciones de pobreza: doce grupos de significados" en Pobreza Un glosario internacional. (Ed. Spicker, Álvarez y Gordon) Buenos Aires: CLACSO, agosto de 
2009 (Edición español), recuperado el 13 de octubre de 2011 de http://bibliotecavirtual.clacso.org.ar/ar/libros/clacso/crop/glosario/

Escuela de Comunicaciones de la Universidad de Viña del Mar (2007): Pobreza: El desafío de (re)construir la noticia. Un estudio en la prensa escrita de la región de Valparaíso. Chile: Fundación para la Superación de la Pobreza, recuperado el 10 de noviembre de 2010 en http://www.comunicacionypobreza.cl/publicaciones/El desafio de (re)construir la noticia 2 $\underline{007 . p d f}$

Thompson, J.B. (1998). Los medios y la modernidad, una teoría de los medios de comunicación en Echeverría Victoria, M. (2007): "Representaciones periodísticas de la Pobreza: perspectivas teóricas para una agenda de investigación", en XIV Anuario de Investigación en Comunicación. México: CONEICC.

\section{Forma de citar este artículo en bibliografías}

GABINO CAMPOS, M. A.; CONTRERAS RAMÓN, R. C. (2011): "La representación de la pobreza en la prensa (Estudio de caso en la prensa tapatía)", en Revista PANGEA, 2, páginas 207 a 220. Red Académica lberoamericana de Comunicación. Recuperado el de de 2 de: http://www.revistapangea.org 